\title{
Quantitative Analysis on Carbide Precipitation in V-Ti Microalloyed TRIP Steel Containing Aluminum
}

\author{
Shiyu $\mathrm{FU}^{1, \text { a }}$, Hui $\mathrm{SI}^{1}$, Hu JIANG ${ }^{1}$, Yanlin $\mathrm{HE}^{1, \mathrm{~b}}{ }^{*}$, Hua WANG ${ }^{1}$ and $\mathrm{Lin}_{\mathrm{LI}}{ }^{1}$ \\ ${ }^{1}$ School of Materials Science and Engineering, Shanghai University, 149 Yanchang Road \\ Shanghai, China \\ afushiyu2012@163.com, bylhe@staff.shu.edu.cn
}

\begin{abstract}
Introducing fine precipitates is an important way to enhance the properties of transformation-induced plasticity (TRIP) steels. In present work, two V-Ti microalloyed TRIP steels containing aluminum with different content were compared. The average size, size distribution and numbers of vanadium-titanium carbides in samples cold rolled, quenched after being held at $800^{\circ} \mathrm{C}$ and quenched after intercritical annealing at $800^{\circ} \mathrm{C}$ and being held at bainitic isothermal transformation temperature of $400^{\circ} \mathrm{C}$ were investigated by using the technique of carbon extraction replica, twin jet chemical polishing thinning and transmission electron microscopy. The carbides were identified to be $(\mathrm{Ti}, \mathrm{V}) \mathrm{C}$ precipitates in steel A and $\mathrm{VC}$ in steel B respectively, precipitated mainly from ferrites grains. The average equivalent radius was $3 \sim 6 \mathrm{~nm}$. Comparison of the experimental results in $\mathrm{A}$ and $\mathrm{B}$ steel revealed low carbon diffusion rate caused by aluminum inhibited the coarsening of vanadium-titanium carbides. The experimental results also showed that $\mathrm{VC}$ carbides dissolution occurred during the intercritical annealing at $800^{\circ} \mathrm{C}$.
\end{abstract}

\section{Introduction}

Transformation-induced plasticity (TRIP) steels exhibit an outstanding combination of high strength and ductility, are considered as good candidates for the third generation advanced high strength steels (AHSS). Introducing fine precipitates by adding alloying elements such as $\mathrm{V}, \mathrm{Ti}$, or $\mathrm{Nb}$ has been one of the notable alternative approaches to further improve the mechanical properties of these steels. The volume fraction, size, morphology and distribution of precipitates have strong effects on the mechanical properties of steel materials [1]. Studies have shown that precipitation strengthening effect of small carbides can significantly improve the mechanical properties of steel [2-4].

In the present work, two $\mathrm{V}-\mathrm{Ti}$ microalloyed TRIP steels containing aluminum with different content were designed and investigated. Vanadium-titanium carbides may

\footnotetext{
* Corresponding author:ylhe@staff.shu.edu.cn
} 
precipitate to increase the strength of ferrite matrix in TRIP steels. The effect of different content on the behavior of carbides in microalloyed steels has been studied for years [5-7]. However, the quantitative analysis of this field is rare, as the difficulty of the experiments. The two steels were held at bainitic isothermal transformation temperature after intercritical annealing. The precipitation behavior of vanadium-titanium carbides was investigated.

\section{Experimental Procedure}

The chemical composition of the TRIP steels studied in the present work is listed in Table 1 . A $100 \mathrm{~kg}$ ingot with the designed composition was produced in a vacuum induction furnace filled with argon and hot rolled to $3 \mathrm{~mm}$ and subsequent cold rolled to $1.5 \mathrm{~mm}$. Table 1. Chemical Composition Of The Steel Studied ( $\mathrm{Wt} \%$ )

\begin{tabular}{|c|c|c|c|c|c|c|}
\hline Steel & $\mathrm{C}$ & $\mathrm{Si}$ & $\mathrm{Mn}$ & $\mathrm{Al}$ & $\mathrm{V}$ & $\mathrm{Ti}$ \\
\hline $\mathrm{A}$ & 0.28 & 0.90 & 2.00 & 1.12 & 0.08 & 0.15 \\
\hline $\mathrm{B}$ & 0.31 & 0.91 & 2.06 & 0.76 & 0.09 & 0.01 \\
\hline
\end{tabular}

Specimens with dimension of $20 \times 20 \times 1.5 \mathrm{~mm}$ were cut and encapsulated. These samples were quenched after being held at $800^{\circ} \mathrm{C}$ and quenched after intercritical annealing at $800^{\circ} \mathrm{C}$ and being held at bainitic isothermal transformation temperature of $400{ }^{\circ} \mathrm{C}$. Carbide particles were chemically extracted in phosphoric acid (2:1) at room temperature and filtered using a micro-porous membrane with $0.25 \mathrm{~nm}$ aperture and dried. A D/MAX-2500 $\mathrm{X}$-ray diffractometer operating at $40 \mathrm{kV}$ and $40 \mathrm{~mA}$ with scanning speed of $4 \%$ min was used to determine the type of precipitates.

Size, morphology, distribution of precipitates and the precipitation location were studied by carbon replica extraction, twin jet chemical polishing thinning and TEM technique. Heat-treated specimen was ground, polished and then etched in 4 vol. $\%$ nital. The carbon film was deposited on the etched surface and scored into $2.5 \times 2.5 \mathrm{~mm}$ square grids before etching again in $8 \mathrm{vol} . \%$ nital. Finally, the specimen was slid into distilled water and the replicas were collected by a copper net and dried. Specimen was also cut and mechanically ground to $\varphi 3 \mathrm{~mm} \times 50 \mu \mathrm{m}$ and further reduced by twin jet chemical polishing thinning for the observation of the precipitation location.

TEM observation was carried out using a JEM-2010F instrument and operating at 200 $\mathrm{kV}$ accelerating voltage. Precipitates were identified by a combination of electron diffraction patterns and energy dispersive spectrometer (EDS) analysis.

\section{Results and Discussion}

X-ray diffraction patterns of carbides after intercritical annealing at $800^{\circ} \mathrm{C}$ and quenched after being held at bainitic isothermal transformation temperature of $400^{\circ} \mathrm{C}$ in $\mathrm{A}$ and B steel were shown in Fig.1. The type of carbides in A and B steel was determined to be $(\mathrm{Ti}, \mathrm{V}) \mathrm{C}$ and $\mathrm{VC}$ carbide respectively. No other types of precipitates were detected for all samples.
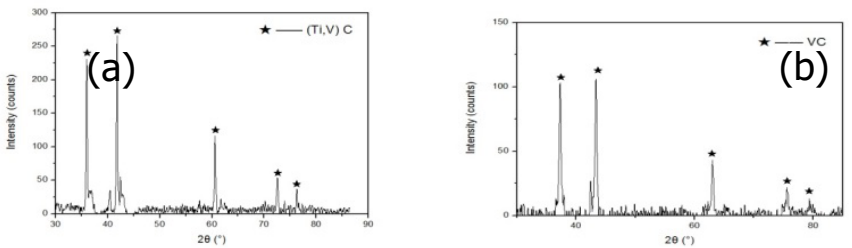

Fig.1. X-ray diffraction patterns of carbides after intercritical annealing at $800^{\circ} \mathrm{C}$ and quenched after being held at bainitic isothermal transformation temperature of $400^{\circ} \mathrm{C}$ (a) in A steel and (b) in B steel. 
Figs. 2 showed the TEM micrographs with electron diffraction pattern and EDS analysis of carbides in A steel and B steel. The carbides were identified to be $(\mathrm{Ti}, \mathrm{V}) \mathrm{C}$ in A steel and VC precipitates in B steel respectively. According to TEM analysis in Fig.3, carbides precipitated mainly from ferrite grains in B steel isothermally held at bainitic transformation temperature, and the same behavior of carbides occurred in A steel.

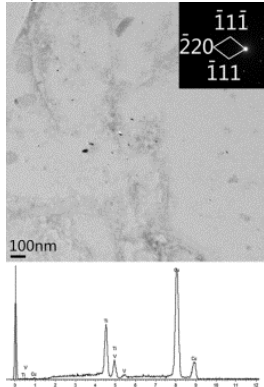

(a)

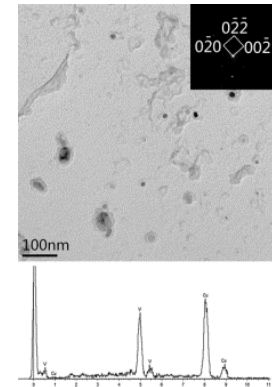

(b)

Fig. 2. TEM micrographs of carbon extraction replica specimens with diffraction patterns and EDS-analysis of $(\mathrm{Ti}, \mathrm{V}) \mathrm{C}$ precipitates in A steel (a) and $\mathrm{VC}$ precipitates in B steel (b) after intercritical annealing at $800^{\circ} \mathrm{C}$ and quenched after being held at bainitic isothermal transformation temperature of $400^{\circ} \mathrm{C}$.

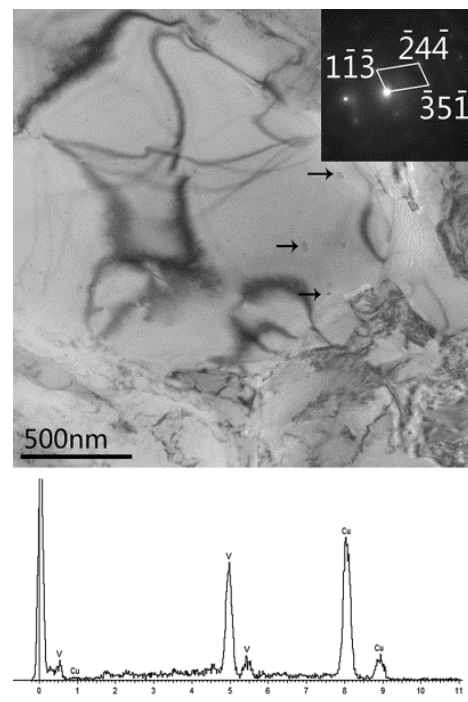

Fig. 3. TEM micrographs of thinning specimen with diffraction pattern and EDS-analysis of VC precipitates in B steel after intercritical annealing at $800^{\circ} \mathrm{C}$ and quenched after being held at bainitic isothermal transformation temperature of $400^{\circ} \mathrm{C}$

In the present work, Qin's [8] method was adopted by drawing the circumference of each precipitate by hand and automatically determining the corresponding diameter of a circle of equal area with Image Analysis System (Image J) . For each steel, more than 300 particles were measured. Determination of the size and its distribution of precipitates was illustrated in Fig. 4 and Fig. 5. 

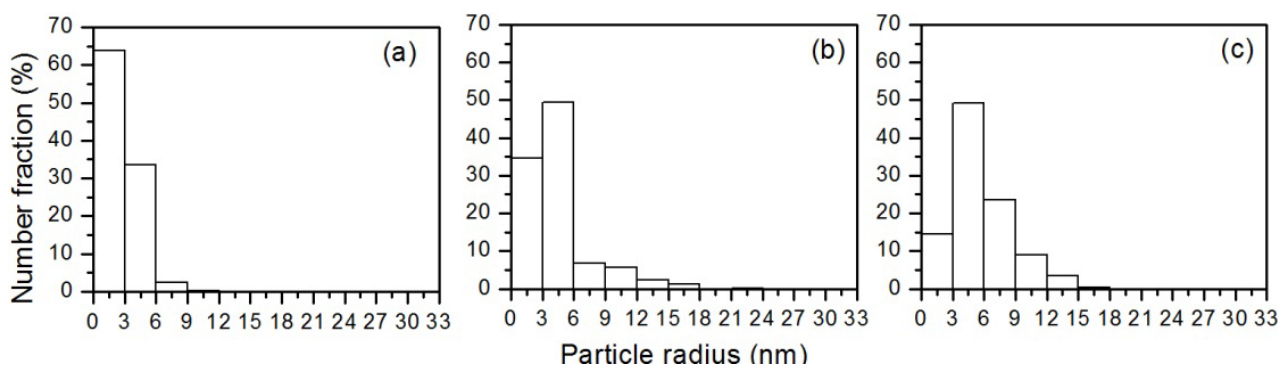

Fig.4. Size distribution of (Ti,V)C carbides in A steel after (a)cold rolling, (b)quenching after held at $800^{\circ} \mathrm{C}$, (c)intercritical annealing at $800^{\circ} \mathrm{C}$ and quenched after being held at bainitic isothermal transformation temperature of $400^{\circ} \mathrm{C}$.
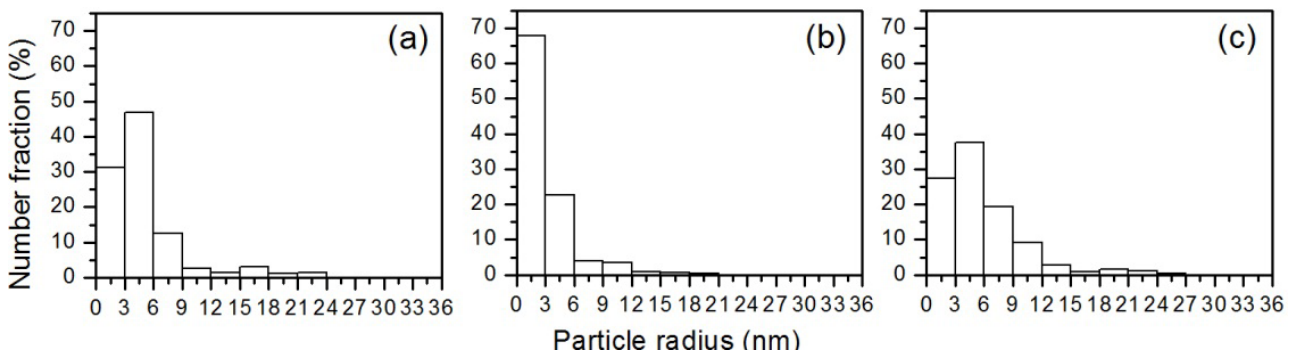

Fig.5. Size distribution of VC carbides in B steel after (a)cold rolling, (b) quenching after held at $800^{\circ} \mathrm{C}$, (c) intercritical annealing at $800^{\circ} \mathrm{C}$ and quenched after being held at bainitic isothermal transformation temperature of $400^{\circ} \mathrm{C}$.

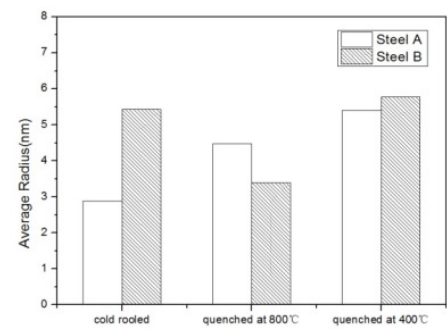

Fig.6. Average radius of $(\mathrm{Ti}, \mathrm{V}) \mathrm{C}$ carbides in $\mathrm{A}$ and $\mathrm{VC}$ carbides in B steel

Combined with figure 4 and figure 5 indicated a higher increment of growth rate of carbides in $\mathrm{B}$ steel. The bigger average equivalent radius of carbides $(\mathrm{Ti}, \mathrm{V}) \mathrm{C}$ carbides in $\mathrm{B}$ steel were detected for the samples after cold rolling and TRIP treatment. In addition, as far as the comparison of intercritical annealed samples and TRIP samples, the gap between A and B steel was obvious - carbides in B steel grew faster. Comparison of the experimental results in $\mathrm{A}$ and $\mathrm{B}$ steel revealed low carbon diffusion rate caused by aluminum inhibited the coarsening of vanadium-titanium carbides.

Comparing Fig.5a and Fig.5b, the average equivalent radius of $\mathrm{VC}$ carbides showed a decreasing trend. This meant that some $\mathrm{VC}$ particles dissolved during intercritical annealing, which coincided with the viewpoints in the previous work [9]. The dissolving behavior of carbides was not obvious in the A steel. The different trends of carbides in A and B steel were especially distinct in Fig.6. 


\section{Conclusion}

(1) The carbides were identified to be $(\mathrm{Ti}, \mathrm{V}) \mathrm{C}$ precipitates in V-Ti microalloyed TRIP steel A and VC in B respectively, precipitated from ferrites grains and grain boundaries. The average equivalent radius was $3 \sim 6 \mathrm{~nm}$.

(2) The average size of $(\mathrm{Ti}, \mathrm{V}) \mathrm{C}$ carbides in heated samples of A steel was less than that of B steel. Comparison of the experimental results in A and B steel revealed that low carbon diffusion rate caused by aluminum inhibited the coarsening of vanadium-titanium carbides.

(3) $\mathrm{VC}$ carbides in B steel dissolved during the intercritical annealing at $800^{\circ} \mathrm{C}$, fitted the viewpoint in the previous work. The dissolving behavior was not obvious in steel A.

\section{References}

1. P. Maugis, M. Gouné, Kinetics of vanadium carbonitride precipitation in steel: a computer model, Acta Mater. 53 (2005) 3359-3367.

2. M.A. Asadabad, S. Kheirandish, A.J. Novinrooz, Microstructural and mechanical behavior of 4.5Cr-2W-0.25V-0.1C steel, Mater. Sci. Eng., A 527 (2010) 1612-1616.

3. Y.J. Chen, J.B. Li, Q.M. Wei, H.Z. Zhai, Preparation of different morphology of TaCx whiskers, Mater. Lett. 56 (2002) 279-283.

4. L.L. Wu, T.K. Yao, J.W. Zhang, F.R. Xiao, Understanding the mechanical properties of vanadium carbides: nano-indentation measurement and firstprinciples calculations, J. Alloys Comp. 548 (2013) 60-64.

5. Baker, T., Processes, microstructure and properties of vanadium microalloyed steels. Materials Science and Technology, 2009. 25(9): p. 1083-1107.

6. Craven, A., et al., Spectrum imaging and three-dimensional atom probe studies of fine particles in a vanadium micro-alloyed steel. Materials Science and Technology, 2008. 24(6): p. 641-650.

7. Show, B., et al., Effect of vanadium and titanium modification on the microstructure and mechanical properties of a microalloyed HSLA steel. Materials Science and Engineering: A, 2010. 527(6): p. 1595-1604.

8. Y. Qin, G. Götz, W. Blum, Z. G. Zhu, "Determination of size distribution of precipitates in the cast martensitic steel G-X12CrMoWVNbN 10-1-1 by direct and indirect method," J. Alloys Comp., 352 (2003), 260-264.

9. L. Yang, S. Liu, G. Zhang, J. Southwest Jiaotong Univ. 29 (1994), 525-530. 